\title{
Developing Mathematical Thinking and Innovation Capability of Students in Engineering Mechanics Teaching
}

\author{
Yan-xia Wang Qing-hui Shang \\ School of Traffic and Vehicle Engineering, Shandong University of Technology, \\ Zibo, China \\ wangyx200@163.com
}

\begin{abstract}
Keywords: Engineering Mechanics; Mathematics; Innovation; Teaching.
\end{abstract}
\begin{abstract}
Engineering mechanics is a course in which a set of theoretical analysis and engineering application is applied, the course originates in the engineering practice with a significant engineering background, and its systematic theory is described by mathematical theory, so the curriculum have higher requirements for students in mathematical thinking and innovation capability. Based on engineering mechanics teaching practice this article analyzes how to cultivate students' mathematical thinking and innovative ability in engineering mechanics teaching considering existing current problems of engineering students education.
\end{abstract}

\section{Introduction}

At present, the problem of engineering undergraduate education is generally low innovation capabilities and a lack of innovative thinking. For example, students can merely solve a series of exercises similar to examples, and lack the ability to analyze and solve problems ,once encountered with the actual topic closely related with practice,they feel at a loss and can not find the breakthrough point to solve the practical problems .One of the key reasons for this phenomenon is that students lack the mathematical thinking and innovation capacity [1].

Mathematics is a form of science that studies the relationship of numbers and form of space, it is the foundation of all science and technology,and is also thinking and problem-solving tools [2]. Engineering Mechanics is a set of theoretical analysis and engineering application of integrated programs including a scientific research on balance law and intensity, stiffness, stability calculations of structure[3],higher requirements are needed for students' mathematical thinking and innovation capabilities.Making rational use of mathematical methods and emphasizing their application in engineering mechanics teaching have a positive impact on the cultivation of students' mathematical thinking and innovation capability, as well as understand the nature of the mechanical problems better[4].

\section{The Relationship between Engineering Mechanics and Mathematics}

From the view of mathematic, two problems should be solved in engineering mechanics teaching, one is to enable students to recognize the importance of mathematics in solving practical problems, the second is to help students master the method of the mathematic modeling, that is to say mathematics is a deductive methodological tools for solving engineering mechanics problems [4].

The Application of Mathematic in Engineering Mechanic. Systematic theory of engineering mechanics is described by the mathematics. Students learned the abstract variables between derivation and operation in the past, and is unfamiliar with the application of mathematics,.when it comes to mechanical problems with engineering backgrounds, each variable is assigned a specific mathematical physical meaning, such as the synthesis and decomposition of force, velocity and acceleration analysis, so that the interpretation of vector in mathematics have specific meanings in mechanics. Through mathematical deduction, the establishment of a series of compliance with the laws of physics mechanics. Through mathematical expressions, helps to further reveal the intrinsic link between objects, so that mechanics can solve complex practical problems more directly, while the students understand the application of mathematics in other areas also played a positive role. 
The Relationship Between Mathematical Thinking and Innovation Ability. Mathematics is a necessary condition for innovation, and innovation means getting research results through innovative thinking process using mathematical thinking tools.

Many students learn mathematics for many years, and grasp it very skilled, innovative thinking may still lack the ability, the reason is because mathematics is a necessary condition of innovation, not a sufficient condition. People of the innovative capacity , are all with good mathematical foundation, use innovative thinking to create a significant mathematics theory. Innovative mathematical thinking is necessary for achieving innovation,and we will not get a major breakthrough in the theory and methods without the use of mathematical thinking in the process of solving problems. Thus, in learning process we must attach importance to mathematical thinking, grasp the mathematical process of innovation thinking and cultivate it. We conclude from above all that, the students ability to innovate not only depend on strengthening mathematical knowledge but also on how innovative thinking can only achieve innovation ability.

\section{The Existing Problems of Current Teaching and Learning}

Existing Problems of teacher in Mechanic Teaching. More skilled teachers teaching content, mostly using modern teaching methods, students' innovative ability but there is also a lot less. For example: When the teacher to explain the problem, the lack of analytical thinking processes, lack of proper analysis of students for innovative thinking; less content with the reality of teaching, the impact of students' learning motivation and interest; teachers on students ability to innovate lack of awareness, etc. .

Existing Problems of Students in Mechanic Learning. Student learning objectives are not clear, the lack of interest in learning. Most students learn in a passive state, few students can reach the realm of interest in learning. Students in learning, as long as the feeling of the teacher's example they will make, they think they have learned to master the curriculum, there is no deep understanding of the problem-solving approach the teacher talked about in the end is how to think out, do not learn to look for problem-solving approach, more no use innovative thinking to create a new problem-solving methods. Many students in learning, learning high school still in use during that class notes, homework after class, exam review for examinations. Although this can obtain a good result, but did not learn to self, do not cultivate self-learning ability and innovation ability. Operating independently of the less, many students have jobs plagiarism phenomenon. For teacher assignments, most students are waiting for the individual students to make reference to their ideas and methods completed. This will inevitably lead to the loss of many students to develop independent thinking, the ability to analyze problems and opportunities for innovative thinking ability.

\section{Teaching Practice}

Teachers explain to students not just open to students a key issue, but let students learn according to their own specific practical problems how to find the key to open the issue, namely to find ways to solve the problem, you should also teach students how problems encountered under create new theories and methods. Therefore, teachers must explain the ideas and methods of the thinking process of the birth of the problem, namely, the methods used are based on what is remembered, and to guide students to learn to use their brains to think, to find or create a new problem-solving methods.

Application of Mathematic in Bending Deformation. In chapter of bending internal force, differential equation of distributed loading, shear force, bending moment is shown in Eq(1),(2):

$$
\begin{aligned}
& \frac{d F_{s}(x)}{d x}=q(x) \\
& \frac{d M(x)}{d x}=F_{s}(x)
\end{aligned}
$$

In the chapter of bending deformation, approximate differential equation of bending deformation curve is shown as follow: 


$$
\omega^{\prime \prime}=\frac{M(x)}{E I}
$$

Integrate $\mathrm{Eq}(3)$ successively and the solution is angle and defection curve equation:

$$
\begin{gathered}
\theta=\int \frac{M(x)}{E I} d x+C \\
\omega=\int\left(\frac{M(x)}{E I} d x\right) d x+C x+D
\end{gathered}
$$

Linking bending deformation with bending internal force and summarizing by mathematic knowledge, the conclusion could be gotten as follows:

\section{Relationship Between Defection Curve and Loading.}

$$
\begin{aligned}
& \omega=f(x) \\
& \omega^{\prime}=\theta(x) \\
& \omega^{\prime \prime}=\frac{M(x)}{E I} \\
& \omega^{\prime \prime \prime}=\frac{F_{s}(x)}{E I} \\
& \omega^{(4)}=\frac{q_{(x)}}{E I}
\end{aligned}
$$

Application of these Formula. We can calculate beam loading by differential equation of deflection curve equation;

A cantilever beam shown in Figure1, its length is L,flexural rigidity is EI,equation of fixed surface is $y=-A x^{3}$.What loads should be placed on beam if we want the beam fit fixed surface without compressive stress acting on surface?

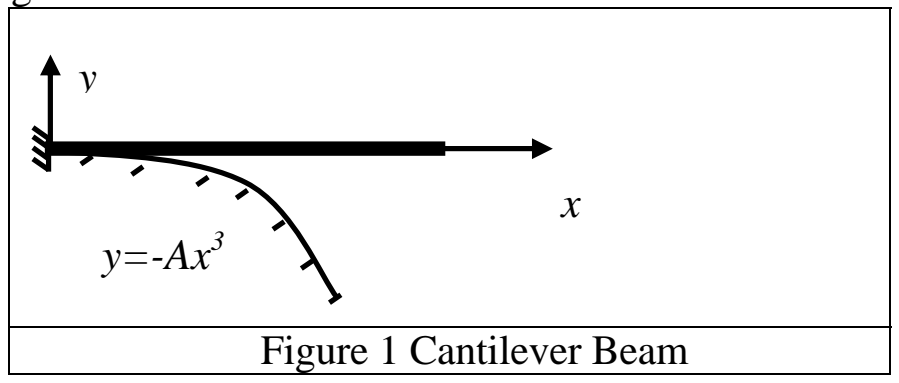

From information above, we know that deflection curve equation is:

$$
y=-A x^{3}
$$

According $\mathrm{Eq}(6)$ to $\mathrm{Eq}(10)$ successively, the force can be deduced as follow:

$$
\begin{aligned}
& \theta=-3 A x^{2} \\
& \frac{M(x)}{E I}=-6 A x \\
& \frac{F_{s}(x)}{E I}=-6 A
\end{aligned}
$$

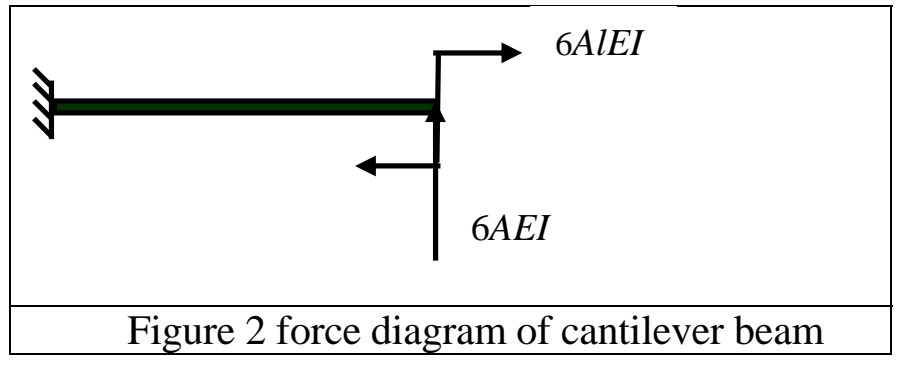


Concentrated force act on free end of cantilever beam, force value 6EI, upward, meanwhile moment6AlEI act on the free end, clockwise. Force diagram of cantilever beam is shown in Figure 2

It develops students' summary ability and stimulate their desire of innovation through such training process.

The Application of Mathematic in Bending Internal Force. Engineering mechanics orients from engineering practice.It is the target of mechanic teaching that creating model and developing students' modeling ability,is also the way to promote comprehensive quality.Previous existing models are given in most teaching materials but the modeling method is not given.As the consequence,students can only solve tasks in books but can do nothing about practical use.

The main trail of thoughts is that firstly extracting model out of engineering problems and secondly transforming mechanic model into mathematic model,then getting solution which can be explained or examined in mechanic. In the process of mechanic teaching,existing simplified mechanic models are given directly ,so the main difficulty for students who is a fresh man in mechanic learning is connecting corresponding mathematical model with mechanic. Students make mistakes in drawing curved beam internal force diagram,and this is a result of not realizing the mechanic model having been transformed into mathematical model,that is to say,not regard internal force equation as function equation, not relate continuation and sudden change with the concept continuation ,gap,limitation of function. As a result ,they can not solve mechanic problems in mathematical method. Teachers should pay attention to finding similarity in mechanic equation and formulation,and help students mastering solving mechanic problems in mathematic method. Through analysis of samples,we can strengthen train of transform mechanic model into mathematic model and make students get principle of solving mechanic problems in mathematic way.thus master solving practical task in mathematic way.

\section{Summary}

It is significant issue of implementing quality-oriented education that how to implement innovative mechanic teaching so as to learn mechanic in innovative way. To use mathematical method properly in mechanic teaching is helpful to both students and teachers,it can not only enforce students' mathematical thinking but also make the teaching process interesting. As a result, it can deepen the understanding of nature describing objective law in engineering mechanics and greatly inspire teachers' research motive as well as students' passion of innovative study. Therefore, the target that teaching,study and use unit together can come true, making students recognize both the charm of mathematic and perfection of the mechanics.

\section{Acknowledgements}

This work was financially supported by the University basic discipline construction - Materials Mechanics and the Shandong provincial high-quality curriculum - Engineering Mechanics.

\section{References}

[1] Changcheng Zhou, Chuanbo Ren, Song Gao, Ruixian Li. "Innovative thinking and graduate student innovation ability training," J Higher engineering education research, 2008 supplement, pp. 26-28.

[2] Institute of ordinary high school curriculum. mathematics. People's education press, 2008

[3] Dai Baoqing, Zhang Donghuan. Engineering mechanics [M]. Beijing: Beijing University of Aeronautics and Astronautics Press, 2010

[4] Zhian Yang, Gaofeng Li, Peiqiang Jia. Teaching practice based on the mathematical induction of "engineering mechanics", J Tangshan college journal, vol.23(3), pp. 42-44,2010

[5] Wang Lijing. Thinking back to the students and innovation into the classroom [J]. Journal of Fujian Institute of Education, 2009,12, pp.44-45 